\title{
Capacity range - definition and calculation
}

\author{
Přemysl Šrámek ${ }^{1}$, Jaromir Široký $\dot{y}^{*}$ and Pavlina Hlavsová ${ }^{1}$ \\ ${ }^{1}$ University of Pardubice, Faculty of Transport Engineering, Department of Transport Technology and Control, Studentska 95,53210 \\ Pardubice, Czech Republic
}

\begin{abstract}
This article defines a new capacity parameter called capacity range (CR). The definition is explained and then the parameter is calculated for a selected section of Kolín - Choceň (overlapping section of RFC 7 and RFC 9). The calculation is based on timetable 2016. Capacity range, expressed as dependence of the number of trains on average delay increment, is a useful capacity parameter particularly for coherent railway sections with remote traffic control.
\end{abstract}

\section{Introduction}

In a doctoral thesis [1], it was found out that it would be appropriate to extend the existing methodologies of calculating capacity parameters (SŽDC D24, UIC 406), particularly by adding parameters allowing for a more network-based calculation of capacity (through several interstation sections). Even though these parameters would be limited by railway network bottlenecks, which they would likely fail to identify, they would still be useful for the evaluation (comparison) of individual operational concepts. At the same time, they would fit the notion that capacity as such actually doesn't exist [2].

With the current implementation of remote traffic control through several interstation sections, it is possible to move trains through bottlenecks more efficiently than before. That's why a new parameter was defined: CR (capacity range).

\section{Objectives}

The aim of this paper is to define a new capacity parameter called capacity range, including the methodology of calculation. Subsequently, this methodology is applied on the section of Kolín Choceň.

\section{Methodology}

To meet the above mentioned objectives, the following methods are to be employed: capacity range calculation, bottleneck identification (operational facility occupancy rate), simulation.

Capacity range calculation - capacity range (hereinafter referred to as CR) definition is shown in Figure 1. CR is defined as an area delimited by 2 lines and 1 curve. Specifically, it is a perpendicular line to the $\mathrm{X}$-axis from the point where $\mathrm{N}=1$ ( $\mathrm{N}$ denoting the total number of trains), and the actual $\mathrm{X}$-axis representing the state where $\mathrm{ADI}=0$. Here, ADI (average delay increment) means average delay increment. The curve then expresses the dependence of ADI on $\mathrm{N}$ in a specific section of infrastructure. Mathematically, the relationship is expressed as follows:

$$
\mathrm{CR}=\left|\int_{1}^{E} f(x) d x\right|
$$

$\mathrm{CR}$ is calculated as an integral of a dependence function of ADI on $\mathrm{N}$, delimited by $\mathrm{N}=1$ on one hand ( $\mathrm{N}$ can be neither negative nor zero), and a point of balance, where ADI $=0 \mathrm{~min} /$ train based on the specified number of trains (based on $\mathrm{f}(\mathrm{x})$ ), on the other hand. With further increasing the number of trains, ADI becomes positive, leading to reduced stability of the timetable and impossibility to limit or eliminate the stochastically

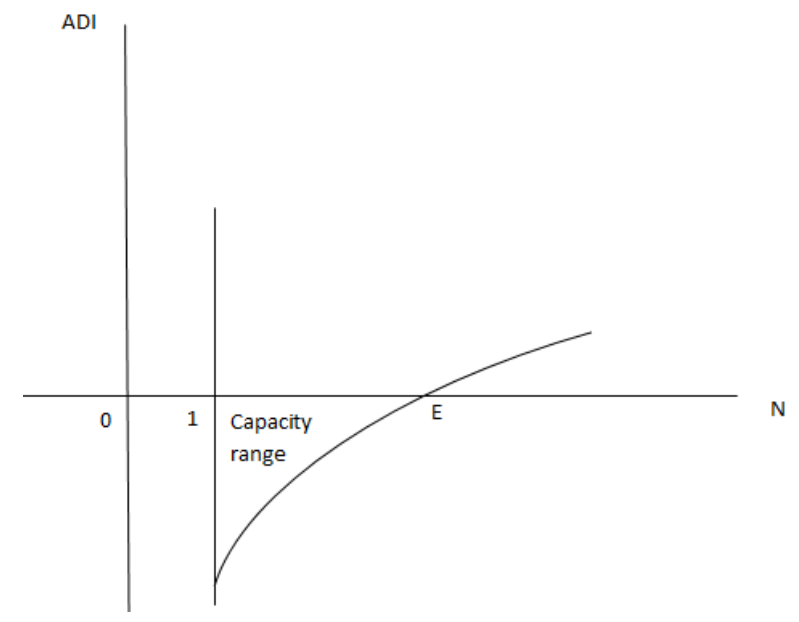

driven delay.

Fig. 1. Capacity range definition.

The average delay increment is calculated according to the following formula:

$$
A D I=\frac{z_{p} \text { exit }-z_{p} e n t r y}{N}
$$

\footnotetext{
* Corresponding author: jaromir.siroky@upce.cz
} 
As such, it is a quotient of the difference between the total exit delay and the total entry delay of all trains, and their total number.

Where the railway infrastructure manager is willing to sacrifice timetable stability to a certain extent to increase the number of trains in the specific infrastructure section, enlarged capacity range can be considered as well (CRE - capacity range enlarged).

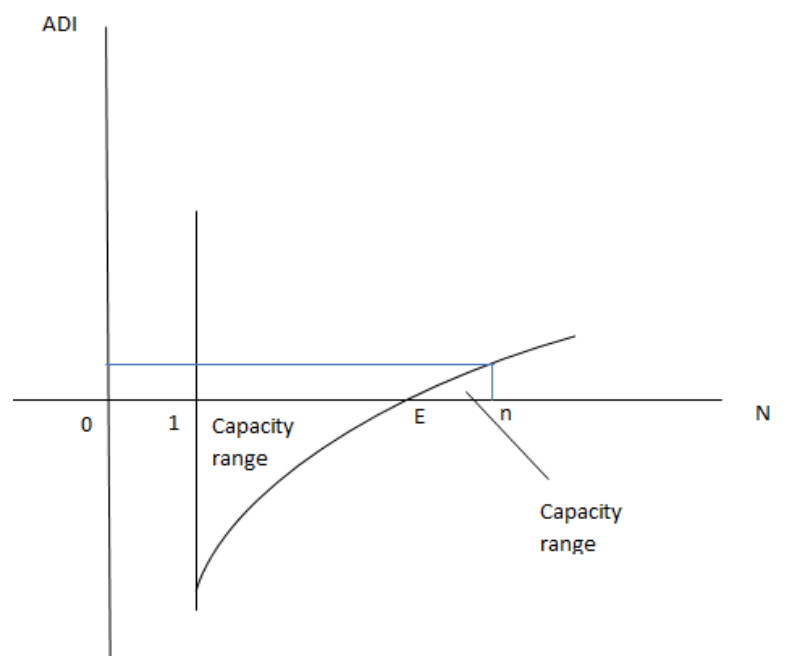

This is shown in Figure 2.

Fig. 2. Enlarged capacity range definition

The capacity range area can optionally be enlarged due to the railway infrastructure manager deciding to operate a higher number of trains at the price of certain instability of the timetable (positive ADI). This actually means increasing quantity at the expense of quality of railway transport. Mathematically, the relationship is expressed as follows:

$$
\mathrm{CRE}=\left|\int_{1}^{E} f(x) d x\right|+\int_{E}^{n} f(x) d x
$$

This gives rise to a new area above the curve $(\mathrm{f}(\mathrm{x}))$ delimited by the $\mathrm{X}$-axis and the point of balance, where $\mathrm{ADI}=0 \mathrm{~min} / \mathrm{train}$, and a set point (either based on the maximum allowable ADI or the required number of trains $\mathrm{N}$ ).

The greatest challenge in calculating capacity range is the calculation of the dependence function $\mathrm{f}(\mathrm{x})$ of $\mathrm{ADI}$ on $\mathrm{N}$, this function being different for different railway infrastructure sections. The calculation is described below in the specific application section.

Identifying a bottleneck - since capacity range is mainly useful for evaluating operational concepts, or lines, it cannot primarily be used to identify a railway network bottleneck. Therefore, operational facility occupancy rate is calculated as an additional parameter, according to the Railway Infrastructure Administration (SŽDC) (ČD) regulation No. D24. This is expressed as the ratio of the total time of occupancy of the operational facility with the regular scope of railway transport to the calculation period reduced by the total time of closures and permanent manipulations. A facility is considered sufficiently occupied having a rate of occupancy within a range of $S_{-^{o}}=0.5$ to 0.67 (1). Mathematically expressed:

$$
S_{0}=\frac{N \cdot t_{\text {obs }}}{T-\left(\sum t_{\text {vfy }}+\sum t_{\text {stal }}\right)}
$$

$$
\begin{array}{ll}
S_{o} & \text { operational facility occupancy rate [-] } \\
T & \text { calculation period [min] } \\
N & \text { regular scope of transport [number of trains / } \\
\text { calculation period] } \\
t_{o b s} \quad \text { technological time of occupancy of a specific } \\
\text { operational facility by one train [min/train] } \\
\sum t_{\text {tyjn }} \quad \text { total time of closures of operational facility } \\
\text { for repairs and maintenance [min] } \\
\sum t_{\text {gtaln }} \text { total time of occupancy of operational facility } \\
\text { due to permanent manipulations [min] }
\end{array}
$$

Simulation - as a simulation program, SimuT was chosen mainly due to the simple determination of timetable stability based on the average delay increment calculated as a quotient of the difference between the exit delay and the entry delay, and the number of trains. Entry delay is entered by the simulation program for individual trains based on exponential probability distribution. Furthermore, SimuT allows for the calculation of capacity parameters according to the SŽDC (ČD) regulation No. D24 [3].

\section{Application of capacity range on the section of Kolín - Choceñ}

In practical application, it is necessary to enter the required data concerning the infrastructure and scope of operation into the programme. Capacity range calculation was performed on part of the 010 line, specifically on the section between Kolín (incl.) and Choceň (incl.) with a total number of 10 railway stations, with 9 of them operated remotely from the Central Dispatching Site (Centrální dispečerské pracoviště) in Prague (station Pardubice hl. n. is not yet operated remotely). Using the GVD 2016 analysis, the average daily scope of railway transport was identified as 384 trains, 171 of which were long-distance passenger service trains (Ex, R), 62 of which were regional passenger service trains (Sp, Os), and 151 of which were freight service trains.

The dependence function $(\mathrm{f}(\mathrm{x}))$ of ADI on $\mathrm{N}$ is determined based on the maximum reliability function created by fitting the curve to individual points. These individual points represent particular ADI values for the given number of trains. The more points are identified, the more reliable will the determination of the function $\mathrm{f}(\mathrm{x})$ be. It would thus be optimal to create the individual points by always adding one train at a time. On the other hand, this solution would be very time consuming and would make the calculation too complex. Therefore it is necessary to set individual steps in the simulation programme to specify the number of trains by which the individual points would differ.

So as not to encumber the steps with a different number of trains of different categories, the trains need to be added in "packages". These packages always need 
to be adapted to the operation on the particular line. As for the section of Kolín - Choceň, where the ratio of trains is 171:62:151 (long-distance passenger service : regional passenger service : freight service), the function $\mathrm{f}(\mathrm{x})$ can be determined using 6 points with one step representing the addition of 30 long-distance passenger service trains, 10 regional passenger service trains, and 25 freight service trains. The overall results for the individual steps including bottleneck identification (operational facility occupancy rate) are shown in Table 1. These are outputs from the SimuT simulation program.

Table 1. Setting Word's margins.

\begin{tabular}{|c|c|c|c|}
\hline Number of trains & $\begin{array}{c}\text { ADI } \\
\text { (min/train) }\end{array}$ & Bottleneck & $S_{o}$ \\
\hline $65(30+10+25)$ & -2.86 & $\begin{array}{l}\text { Pardubice hl. n. } \\
\text { - Přelouč, TK } 1\end{array}$ & 0.10 \\
\hline $130(60+20+50)$ & -2.48 & $\begin{array}{l}\text { Pardubice hl. n. } \\
\text { - Přelouč, TK } 1\end{array}$ & 0.20 \\
\hline $195(90+30+75)$ & -1.87 & $\begin{array}{l}\text { Pardubice hl. n. } \\
\text { - Přelouč, TK } 1\end{array}$ & 0.28 \\
\hline $260(120+40+100)$ & -0.99 & $\begin{array}{l}\text { Pardubice hl. n. } \\
\text { - Přelouč, TK } 1\end{array}$ & 0.39 \\
\hline $325(150+50+125)$ & 0.37 & $\begin{array}{l}\text { Pardubice hl. n. } \\
\text { - Přelouč, TK } 1\end{array}$ & 0.48 \\
\hline $390(180+60+150)$ & 2.17 & $\begin{array}{l}\text { Pardubice hl. n. } \\
\text { - Přelouč, TK } 1\end{array}$ & 0.57 \\
\hline
\end{tabular}

As can be seen from Table 1, ADI increases with the individual steps. In each of the steps, the interstation section Pardubice hl. n. - Přelouč (the first track rail thereof) was identified as a bottleneck. This fact reflects the overall consistency of the calculation and shows that the operational facility occupancy rate increases with the individual steps as well.

The dependence function $\mathrm{f}(\mathrm{x})$ of $\mathrm{ADI}$ on $\mathrm{N}$ can also be expressed as follows:

$$
A D I=f(N)
$$

The results of the individual steps corresponding to the above mentioned equation are shown in Figure 3.

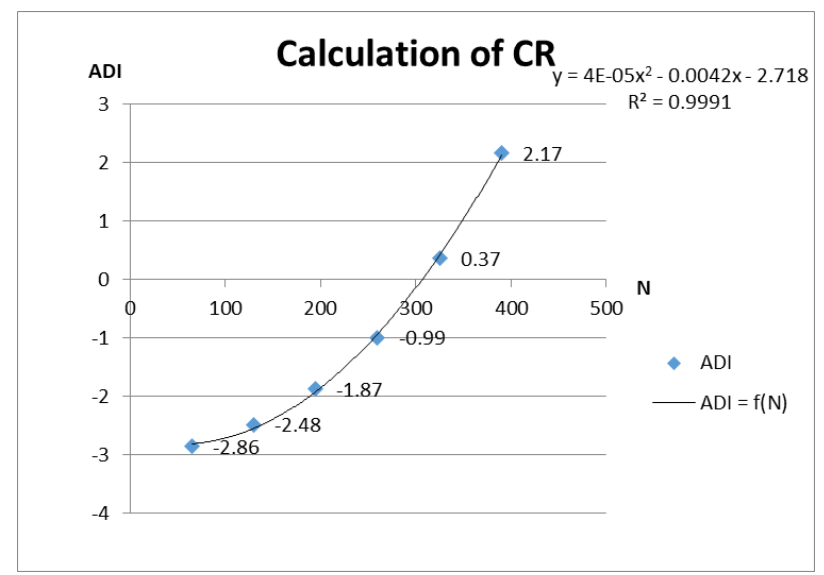

Fig. 2. Dependence of ADI on $\mathrm{N}$ - specific CR

Individual points were fitted to a trendline with the highest reliability; the dependence of ADI on $\mathrm{N}$ is polynomial, and in this case quadratic. Or:
$A D I=0.00004 \cdot N^{2}-0.0042 \cdot N-2.718$

The capacity range formula can also be expressed as follows:

$$
\mathrm{CR}=\left|\int_{1}^{E} f(N) d N\right|
$$

Point $\mathrm{E}$ can be calculated by inserting $\mathrm{ADI}=0$ $\mathrm{min} /$ train into the above mentioned equation, which gives rise to a standard quadratic equation:

$$
0=0.00004 \cdot N^{2}-0.0042 \cdot N-2.718
$$

Based on the rules for calculating quadratic equations, the result is as follows:

$$
\begin{gathered}
E_{1}=318.4 \\
E_{2}=-213.4
\end{gathered}
$$

As it is a total number of trains, the number must be positive and integral. To maintain the timetable stability, $\mathrm{E}$ is always rounded down. The resulting point of balance is then $\mathrm{E}=318$ trains. Given the original ratio $3: 1: 2.5$, one of the possible optimum solutions of transport structure on the given section would be 147 long-distance passenger service trains, 49 regional passenger service trains, and 122 freight service trains. With this transport structure, the timetable is still stable, i.e. able to reduce random delay. Now we can calculate capacity range:

$$
\begin{gathered}
\mathrm{CR}=\left|\int_{1}^{318}\left(0.00004 \cdot N^{2}-0.0042 \cdot N-2.718\right) d N\right| \\
\mathrm{CR}=\left|\left[0.00001333 \cdot N^{3}-0.0021 \cdot N^{2}-2.718 \cdot N\right]_{1}^{318}\right| \\
\mathrm{CR}=645.2
\end{gathered}
$$

Capacity range of the section Kolín (incl.) - Choceň (incl.) for further use (comparison of operational concepts, modifications of infrastructure) is 645.2.

\section{Application of enlarged capacity range on the section of Kolín - Choceñ}

As described above, capacity range can be increased at the expense of reduced timetable stability (at the price of increasing ADI). In this article, both cases are described below, i.e. CR for the required number of 450 trains, and $\mathrm{CR}$ for an allowable ADI of $5 \mathrm{~min} /$ train.

Enlarged capacity range for $\mathrm{N}=450$ - where as requested by railway undertakings, the railway infrastructure manager comes to a conclusion that it is necessary to operate 450 trains a day, while maintaining the current transport structure (the ratio of $3: 1: 2.5$, i.e. in this case 208 long-distance passenger service trains, 69 regional passenger service trains, and 173 freight service trains) on the existing infrastructure, ADI can be predicted using the identified function as follows:

$$
\begin{gathered}
A D I=0.00004 \cdot N^{2}-0.0042 \cdot N-2.718 \\
A D I=0.00004 \cdot 450^{2}-0.0042 \cdot 450-2.718 \\
\text { ADI }=3.492 \mathrm{~min} / \text { train }
\end{gathered}
$$


The operation of 450 trains while maintaining the current transport structure would probably lead to an increase of average delay increment by $3.492 \mathrm{~min} /$ train. Capacity range will be enlarged using the formula for CRE:

$$
\begin{gathered}
\mathrm{CRE}=\left|\int_{1}^{E} f(N) d N\right|+\int_{E}^{n} f(N) d N \\
\mathrm{CRE}=645.2+ \\
{\left[0.00001333 \cdot N^{3}-0.0021 \cdot N^{2}-2.718 \cdot N\right]_{718}^{450}} \\
\mathrm{CRE}=645.2+214.6 \\
\mathrm{CRE}=859.8
\end{gathered}
$$

Capacity range was enlarged by an optional part (214.6) to 859.8.

Enlarged capacity range for an allowable ADI of 5 $\mathrm{min} /$ train - the railway infrastructure manager can also accept a timetable with a certain positive average delay increment to be able to offer a higher number of train routes. In this case, the following applies:

$$
\begin{gathered}
\mathbf{5}=\mathbf{0 . 0 0 0 0 4} \cdot N^{2}-0.0042 \cdot N-\mathbf{2 . 7 1 8} \\
\mathbf{0}=\mathbf{0 . 0 0 0 0 4} \cdot N^{2}-\mathbf{0 . 0 0 4 2} \cdot N-\mathbf{7 . 7 1 8} \\
\mathrm{N} 1=494.9 \\
\mathrm{~N} 2=-389.9
\end{gathered}
$$

As it is a total number of trains, the number must be positive and integral, and always rounded down, as described above. The total number of trains for an allowable ADI of $5 \mathrm{~min} /$ train is $\mathrm{N}=494$ trains. Given the original ratio 3:1:2.5 (maintaining the current transport structure), it is possible to operate 228 longdistance passenger service trains, 76 regional passenger service trains, and 190 freight service trains on this section and with this allowable ADI. Capacity range will be enlarged using the formula for CRE:

$$
\begin{gathered}
\mathrm{CRE}=\left|\int_{1}^{E} f(N) d N\right|+\int_{E}^{n} f(N) d N \\
\mathrm{CRE}=645.2+ \\
{\left[0.00001333 \cdot N^{3}-0.0021 \cdot N^{2}-2.718 \cdot N\right]_{318}^{494}} \\
\mathrm{CRE}=645.2+400.1 \\
\mathrm{CRE}=1,045.3
\end{gathered}
$$

Capacity range was enlarged by an optional part (400.1) to $1,045.3$.

\section{Conclusion}

With the current implementation of remote traffic control through several interstation sections, it is possible to move trains through bottlenecks more efficiently than before. In this article, capacity range was thus defined analysing the function of average delay increment in a given infrastructure section, allowing for a more network-based evaluation of capacity.

On the other hand, the use of this methodology is problematic mainly in relation to integral calculus, or the need to phase the calculation depending on the local course of the function.

In addition to the possibility of network-based capacity evaluation, another advantage of capacity range is the possibility to predict the delay increment based on a set number of trains or the number of trains according to the maximum allowable delay increment.

The work was supported from ERDF/ESF "Project PosiTrans - University of Pardubice cooperation and application sphere in application oriented research of localization, detection and simulation systems for transport processes" (No. CZ.02.1.01/0.0/0.0/17_049/0008394) and "Student grant competition“(No.SGS_2018_023).

\section{References}

1. P. Sramek, Vliv periodického jízdního řádu na kapacitu trati. Pardubice: doctoral thesis, 2017.

2. International Union of Railways (UIC). UIC CODE 406, 2nd edition. Paris: UIC, 2013. ISBN 978-27461-2159-1.

3. P. Sramek, T. Molkova, Horizons of Railway Transport 2016 - proceeding, 207-213. (2016)

4. J. Siroky, et al. Transport Technology and Control. Tribun EU. Brno. pp. 238. (2014).

5. J. Gasparik, J. Majercak, J. Siroky, B. Abramović, P. Mesko, P. Nachtigall, V. Zitricky. Railway Traffic Operation. 292 p. 2017

6. J. Gasparik, B. Abramovic, V. Zitricky, Technicki Vjesnik - Technical Gazette. 25, 4 1190-1195, (2018)

7. J. Gasparik, J. Siroky, L. Peceny, M. Halas. Communications: scientific letters of the University of Zilina. 2. 25-30.(2014)

8. P. Sramek T. Molkova,. Proceedings of the Third International Conference on Traffic and Transport Engineering (ICTTE). 949 - 954. (2016) 